sciendo

DOI: 10.2478/RAE-2019-0039 Review of Artistic Education no. 182019 347-352

\title{
9. HISTORY AND MODERNITY IN ARTISTIC EDUCATION FROM ROMANIA
}

Eugenia Maria Paşca ${ }^{316}$

\begin{abstract}
The issue of artistic education is not new, it is still concerned and concerned by many specialists. The newities emerged and imposed from time to time in the evolution of culture and education were and are determined by the scientific and artistic achievements, the enrichment of the possibilities of knowledge and valorization of the experiences and achievements, both from the field of artistic didactics, as well as from musical creation and interpretative art. The perspectives, especially in the last half century, aimed at increasing the knowledge of the child's physical and mental peculiarities, his ability to form audiences, visions and chinestecs, and the fundamental aims pursued by specialists - teachers and researchers - have been and have continued to improve the contributions of music, literature and dance to the aesthetic and ethical education of children, to developing their sensitivity and intelligence, in other words, to the formation and harmonious development of the children's personality. From the perspective of knowing and preserving the national identity, in the non-formal educational system existing in Romania, there are musical-literarychoreographic circles with folkloric specifics organized in the Children's Clubs and Palaces. Also, through school curriculum (CDS), there are initiatives by music education teachers to capitalize on music-literary-choreographic folklore through new disciplines, giving pupils the knowledge of local, regional and national traditions.
\end{abstract}

Key words: artistic education, creativity, non-formal education, school curriculum, folklore

\section{Introduction}

Folklore has always been one of the ways artistic and implicitly musical education was done. Taking into account the value per se of folklore, and hence its educational vocation, folklore not only enlightens the people, but it also disciplines them, reflecting the moral qualities and noble nature of the people. The songs, dances, various popular beliefs, the yearly or family traditions have always been landmarks in the lives of the Romanians. Folk creations speak to us about the life and mentality of the village people with the help of cultural and aesthetic messages. Students need to know musical, literary and choreographic folklore productions, which are often preferred to other creations because they can directly express a certain state or a certain attitude to the diversity of life's realities. The intense experience of life's events by means of a very refined and subtle artistic language is to be observed in folklore creations. With these considerations in mind, teachers look to awaken students' interest into getting to know and practise Romanian folklore by suggesting specific extracurricular activities.

\footnotetext{
316 Profesor PhD., "George Enescu" National University of Arts from Iaşi, Romania, email:
} eugenia_maria_pasca@yahoo.com 
In addition to creating the second folklore archives of the Romanian Composers Society, Constantin Brăiloiu also needs to be credited for establishing the optional Folklore course, introduced in the curricula of the Conservatory he was managing for the following reasons: "The curricula of musical education insist with the music teachers, regardless of the musical subject they teach, to rely on our traditional song in their teaching. On the other hand, it is certain that there is a growing need for musicians who are familiar with modern scientific methods in order to be able to find and record folk music." (Tiberiu Alexandru, T., 1994, p.47). From the words of the great folklorist and "fed up" with the large number of creations written in the traditional style, but not as authentic as created by our ancestors, there is serious work to select the material and to guide the students in choosing significant works, trying to keep them in a form worth of our ancestors' trust.

Non-formal education offers a set of necessary social experiences, useful for each child as they complement other types of education by: valorising students' spare time from an educational point of view, opportunities for the valorisation of students' life experiences through a more flexible and more open environment and a more diverse everyday learning experience, volunteer work, individual or collective, flexible ways of answering students' interests - a wide range of activities it suggests and the possibility of each student which activities to attend, developing life skills and preparation of teenagers to become active citizens, in addition to the information and competences specific to various activity fields the projects and the non-formal activities fall into, students also develop organisational skills, self-management skills, time-management skills, critical thinking, adopting decisions or solving problems, an environment to practise and cultivate various aptitudes and talents in arts, culture, sports, technical or scientific fields.

The classes of musical education included in the school curriculum or in the artistic - folkloric clubs with Students' Clubs and Palaces have as objective the formation and development of artistic skills by valorising musical, literary and choreographic practice. These institutions were established after 1st June 1950 in many towns of Romania. The Students' Palaces (located in all county capital cities) and the Students' Clubs (located in the other towns or villages with large school population in the county have become powerful institutions very attractive to children, which have diversified the contents and methodology of their specific activities, thus improving their educational offer. They are today methodological centres for extracurricular activities in the technical, scientific, cultural and artistic and sports fields. These clubs have an essential contribution in stimulating and developing children's and teenagers' creativity, in developing their sense of beauty and educating their sensitivity. They play an important role in organising children's spare time, their entertainment through the aesthetic ambience they create, preparing children to spend their spare time in a pleasant and cultivated way. 


\section{Discussions}

The formative role is ensured by the versatility of forms and methods, by stimulating initiatives, inventive spirit, by cultivating aptitudes and talents, orienting and valorising interests and passions, discovering and asserting vocational aptitudes. We must add the fact that these clubs were established in rural areas as well, thus offering equal chances to all children in their artistic, technical-scientific or sports training. Through emotional excellence, music raises students' interest from the earliest age due to its specificity which addresses emotions. This is why aesthetic education through song and audition is important as it rounds up teenagers' personality by knowing aesthetic values and developing the capacity to appreciate and enjoy beauty and developing artistic abilities. Through their contents, aesthetic and musical values contribute to enlarging knowledge on reality, educating aspiration and the desire to introduce beautiful elements in everyday life, to adopting a civilised and sensitive attitude in human relations. The existence of institutions where children and teenagers develop their aptitudes and aspirations is necessary even now, at the beginning of the third millennium.

As the educational system nowadays focuses mainly on cult and less folkloric values, by predominantly oral practice, with the Students' Clubs and Palaces, children may receive guidance to understand and learn folkloric traditions. Extracurricular activities can offer a diverse musical training to passionate and musically endowed students. In these musical clubs in schools and in the above mentioned institutions, students learn to consolidate their musical knowledge, their vocal or instrumental, literary or choreographic interpretation skills, thus justifying the educative function and ensuring the organising of the participants' spare time. The recreational function becomes manifest in active recreation, relaxing programmes and is completed by the aesthetic-entertaining function by which children take part in interesting and diverse actions, both during the school year and during the holidays.

The work groups are made up based on age categories: preschool (5-6 years), primary school students (preparatory class to $4^{\text {th }}$ grade), secondary school students (grades $5^{\text {th }}$ to $8^{\text {th }}$ ) and high school students (grades $9^{\text {th }}$ to $12^{\text {th }}$ ). The work techniques and contents will be adapted to each age group. It is known that the final purpose is to develop aesthetic attitude, to prepare the future adults to become knowledgeable listeners of aesthetic values and possibly music interpreters or creators. The moulding of personality is obvious through music, through the positive enrichment of personality traits, of the character and aptitudes. The study of music has two levels: informative-theoretical and formative-applicative. Going through these activities implies two levels.

The first level aims at developing reproductive - interpretative skills and aptitudes. Based on the contact with the musical phenomenon, the child develops representations, notions, categories, value judgements, theoretical culture is formed and also musical language and its decoding. The second level 
refers to the just attitude to aesthetic values through sensitivity, emotions, and the capacity to listen to, sing, interpret and create artistic values. The interference with intellectual education proves itself by the cultivation of imagination, thinking, originality, motivation for performance, especially for taking part in shows and contests. Moral education is also performed through these group activities which require discipline to work together, respect and collaboration. The contents of the texts consolidate character traits such as love for the family, for the beautiful places in one's country, respect for history. Physical education means movement, and this element is aroused by the sound phenomenon, especially in the interpretation of pop and folk music. Choreography mixed with excessive interpretation mean an adequate interdisciplinary education. Students' participation in the activities of musical assemblies offers them the possibility to complete the musical education received in school or kindergarten, based only on singing and listening. The training in vocal-instrumental bands contributes to the development of musical aptitudes and skills. In the choice of repertoires, one must take into account the children's age: the melody should be clear, accessible; the rhythm must be simple, and the text and harmony adequate. (Paşca E. M., 2009, p. 7-9)

\section{Results}

Thus, modern pedagogy defines this type of activities as those actions carried out under the supervision of a teacher, but not included in the school curriculum and educational plan. They have the role to complete and enlarge the accumulations from the educational system, to valorise and develop the students' interests and aptitudes, coming to support the good organising of their free time. As complementary activities to didactic activities, they have some particularities regarding students' participation, in terms and content and duration, organisational forms and used methods, and result evaluation. Students' participation is based on volunteering and is not compulsory, and the teacher only gives some suggestions regarding their participations in some activities. The contents of activities are set depending on the students' preferences, and on the conditions and possibilities. As regards organisation forms, these are more flexible, focusing on creative imagination of both students and teachers, with a special accent on the students' initiative. (Paşca, E. M., 2009, p. 18-23).

Artistic extracurricular and out of school activities can have various forms depending on the number of participants and the way they are realised (frontal, group or individual) and the location (school, non-formal educational institutions or cultural institutions). From the national analysis we have noticed that there are the following types of clubs: vocal interpretation - individual or folklore group, folklore dances, folklore theatre, folklore orchestra, folklore assemblies. The valorisation of results represents opportunities for knowledge, communication and talent hierarchy through contests and festivals - at local, 
county, regional or national level - advertised in the media. At the level of the School Inspectorates and Ministry of Education there are such preoccupations for the agenda of specific contests for traditional folklore manifestations.

Students know that folk music and dress, theatre and dance represent the most important components of a nation's traditions. They proved that they have understood the importance of the reactivation and reorganisation of this field by what they started to do under the supervision of the teacher during the carried out activities. Having activities to valorise local, regional or national folklore represents the way for students to prove that they are educated both in their families and in school in the spirit of love for our national tradition. In our school, folklore is used and updated through the cultural artistic manifestations that involve students and teachers. In order to transmit from generation to generation the beauty of folklore creations and to keep traditions alive, students are initiated into these extracurricular activities of song and its interpretation, or of dancing and of collecting these priceless folkloric gems. It is the only way to create generations of students who will know how to cherish traditions.

\section{Conclusions}

Artistic education focuses on cultivating the students' sensitivity, on developing his aesthetic faculties and on the joy music and the practice of music must have on the student. The music lesson has the role to familiarise students with the true values of musical art. The lesson of musical education, as part of the Educational School System, focuses on the basis on approaching music through musical genres, as well as on selecting contents with artistic value. Due to everything mentioned above, in order for the musical education lesson to reach its goal, we must take the following into account:

- theoretical elements reduced to the bare minimum necessary for music reception and interpretation;

- turning musical education classes in lessons about art, thus exceeding the standard of activities which speak about music;

- creating motivation and attitudes to get to know artistic beauty and to combat elements of kitsch, surrogates of Romanian art that have surfaced over the years or during present times;

- developing students' emotional lives, awakening their creative powers, with beneficial contributions to the developing of their personality;

- ensuring the open dynamic character of musical education with extensions and links to social and cultural life.

From the point of view of education, artistic activities can be conceived as promotion of authentic values with a focus on aesthetic, moral and educational characteristics. The entire activity of the educator and of the student focuses around them. Important for these endeavours are: testing students' musical taste through conversation or a simple questionnaire which should unveil the social background of the child, his/ her artistic aptitude, his/ her favourite musical 
genre, how often he/ she listens to/ watches various musical productions. Artistic education can be carried out both during classes and outside classes, during extracurricular activities, during the various activities suggested by the school or by the local community to which we are invited or by participating in various festivals and contests, on which occasion we are evaluated by someone else or we are evaluators ourselves. It is a very good type of exchange which develops competition and fair play in students.

The activities that include folklore in their repertoire are considered educational, a source of knowledge, inspiration, an aesthetic factor, inviting the audience to meditate, relax and implementing the idea of filling in some notions. Folklore represents a school of patriotism, which can teach love for the country and the dignified moral attitude our nation has shown in its darkest hours.

\section{References}

1. Alexandru, T. (1994) - Constantin Brăiloiu şi Institutul de Folclor muzical, în Centenar Constantin Brăiloiu Editura Muzicală, Bucureşti

2. Amabile, T. M. (1992). Growing Up Creative: Nurturing a Lifetime of Creativity (2nd ed.). Buffalo, New Zork. Creative Education Foundation.

3. Limbos, E. (1988). Les barrages personnels dans les rapports humains. Paris. ESF.

4. Pașca, E. M. (2009) Dimensiuni ale educaţiei artistice, vol. V, Managementul activităţilor muzicale extracurriculare în educaţia formală şi nonformală, Editura Artes, Iaşi

5. Paşca, E. M. (2014). Specific educational measures for the promotion of artistic excellence at early ages. Review of Artistic Education, 7/8, 298-303, Editura Artes, Iaşi

6. Pașca, E. M. (2015). A new vision of music education from an intercultural perspective for Rroma and non Rroma students. Review of Artistic Education, 9/10, 323-330, Editura Artes, Iaşi

7. Pașca, E. M. (2016). Variables and Constants in the Curriculum for the Music Specialisation of the Romania University Education. Review of Artistic Education, 11/12, 254-262, Editura Artes, Iaşi

8. Pașca, E. M. (2017). A research of the musical education at George Breazul and Dmitri Borisovich Kabalevski. Review of Artistic Education, 15/16, 80-86, Editura Artes, Iaşi

9. Pașca, E. M. (2018). Artistic Education, a promoter for the development of School Creativity from the Inter-Cultural Perspective. Review of Artistic Education, 15/16, 289-297, Editura Artes, Iaşi 